\title{
Dyslipidemias as generating issue in Biochemistry classes
}

\author{
Lima, R. M. ${ }^{1}$, Barreto, K. G. ${ }^{1}$, Silva, L. G. ${ }^{1}$, Marcelino, V. S. ${ }^{1}$ \\ ${ }^{1}$ Laboratório de Biologia, IF Fluminense, Campus-Centro.
}

The traditional didactic model is based on the transmission of the teacher's encyclopedic knowledge. In this model, the teaching of Science aims at the transmission of dominant values, regarded as absolute truths. The teacher is seen is an expert on scientific contents who transmits them to students without motivating them, and without taking into consideration their previous ideas and life experience. This model contributes to the formation of professionals who accept those values uncritically. An effective approach to break up this traditional teaching model in Biochemistry is the use of a generating issue. A Generating Issue is the starting point to the knowledge construction process which, in turn, replaces traditional models. Thus, this study aimed at developing a lesson for a 12th grade class at IF Fluminense on the following content: alcohol, carboxylic acid, ester, and esterification reaction, using dyslipidemias as the Generating Issue. To verify the value of such methodology in Biochemistry classroom, data was collected by applying a questionnaire and images with texts produced by students. In addition, they had a class based on the methodology known as Three Pedagogical Moments, proposed by Delizoicov et al. (2007). Several didactic resources designed by the authors were used, such as slide presentation, tridimensional molecular models, and a roulette game named "Bioquimicados", based on the Facebook game "Perguntados" ("Trivia Crack") . After this, students developed more grounded scientific concepts, making use of terms common in scientific language. This suggests that the use of the Generating Issue in a lesson based on problematization, and supported by a ludic activity, provided a meaningful contribution to improve the students' understanding of the scientific content. This type of non-traditional class promotes greater student motivation, resulting in meaningful learning.

Key Words: Biochemistry, Generating Issue, Dyslipidemias. Supported by: IFF Campus Campos-Centro 